\title{
Formação e educação permanente para produzir boas práticas em saúde mental
}

\section{Training and permanent education to produce good practice in mental health}

\author{
Elisabete Ferreira Mângia ${ }^{1}$
}

Em nosso país, o novo modelo assistencial em saúde mental tornou-se realidade. A significativa expansão das redes de serviços comunitários de saúde mental, estruturadas em torno aos Centros de Atenção Psicossocial em articulação com as ações básicas de saúde, possibilitam o acesso e o cuidado baseado no respeito aos direitos e no exercício da cidadania (Brasil, 2007).

Neste momento, além de avaliarmos necessidades ligadas à ampliação da cobertura assistencial das redes de serviços, é fundamental refletirmos sobre as necessidades de consolidação do modelo e de sua continuidade e sustentabilidade política, cultural e técnica. Para tanto os processos de formação e educação permanente, planejados e desenvolvidos de forma articulada e de acordo com os princípios da saúde mental comunitária e da educação interprofissional, são essenciais para qualificar os serviços, equipes e garantir o avanço do novo modelo.

Para isso devemos fortalecer as articulações entre a saúde mental e as estratégias desenvolvidas para concretizar a diretriz constitucional que confere ao SUS a missão de ordenar os processos de formação dos recursos humanos em saúde de forma a: Interferir nas Diretrizes Curriculares Nacionais (Brasil, 2001), sistematizando e construindo conteúdos específicos para a formação em saúde mental comunitária e colocar a Saúde Mental nos programas e projetos de educação desenvolvidos pelo Ministério da Saúde, especialmente nos âmbitos do Pró Saúde, PET-Saúde, Residência Multiprofissional e nos Núcleos de Apoio à Saúde da Família.

É importante ressaltar que muitos dos princípios e práticas hoje adotados mais amplamente na saúde, tais como humanização, vínculo, acolhimento, a difusão das práticas grupais, a horizontalização das relações entre usuários e profissionais, etc, são originários dos processos de reformas psiquiátricas. Essas contribuições mostram o papel diferenciado que saúde mental desempenha no conjunto dos processos de formação e organização do trabalho em saúde e validam a importância da participação da saúde mental nos diversos projetos de formação em saúde (OMS/OPAS, 2001).

Em articulação com os aspectos já apresentados, se coloca a necessidade da definição de estratégias específicas da saúde mental no contexto da Política Nacional de Educação Permanente em Saúde, recentemente regulamentada pela Portaria GM/ MS n ${ }^{\circ} 1.996$, que definiu diretrizes e estratégias para a implementação, tramitação e financiamento das Ações de Educação na Saúde que passaram a compor o Pacto de Gestão, do Pacto pela Saúde (Brasil, 2007).

Embora ainda pouco discutida no âmbito específico da Saúde Mental, a nova Portaria definiu como componente do primeiro grupo de critérios, para a distribuição de recursos aos municípios, a cobertura de centros de atenção psicossocial, ao lado da cobertura de equipes de saúde da família e equipes de saúde bucal. Ou seja, colocou o desenvolvimento das redes de saúde mental como uma de suas 3 prioridades.

Nesse contexto é importante o desenvolvimento de esforços na articulação e participação organizada e coordenada de representantes de todos os segmentos da saúde mental nas CIES além da construção de estratégias de educação em saúde comuns, adequadas e articuladas á consolidação das redes de serviços de saúde mental. Assumir esse desafio pode contribuir para viabilizar um projeto nacional consistente na direção da formação e aprimoramento dos recursos humanos em saúde mental.

\footnotetext{
${ }^{1}$ Editora da Revista de Terapia ocupacional da USP, docente do Curso de Terapia Ocupacional da FMUSP
} 
Rev. Ter. Ocup. Univ. São Paulo, v. 20, n. 2, p. i-ii. maio/ago. 2009.

Os serviços de saúde mental dependem muito mais de recursos humanos do que de equipamentos tecnológicos, para conduzir os tratamentos e sustentar relações terapêuticas. A habilidade dos profissionais é central e influencia os usuários na escolha, adesão e continuidade dos tratamentos, de forma que a natureza do trabalho em saúde mental implica em grande envolvimento psico-afetivo com riscos de sobrecarga que podem prejudicar o papel profissional e a qualidade da assistência. Assim, o recurso humano deve ser visto como um componente dinâmico que necessita apoio e investimento permanente (Merhy, 2005).

Como fazer a gestão do pessoal na perspectiva da saúde mental comunitária, é um assunto ainda pouco discutido e merece atenção quando se trata de processos formativos. Processos de seleção e de aquisição de competências clínicas devem ser pensados de acordo com as novas diretrizes dos serviços e não de forma desvinculada.

O novo modelo de cuidado em saúde mental requer muito investimento na formulação e desenvolvimento do trabalho em equipe capaz de conhecer e responder às necessidades sociais e de cuidado em saúde do conjunto da população sob sua responsabilidade. Mas especificamente e a partir da definição de prioridades, a equipe deve produzir e acompanhar projetos terapêuticos participativos e orientados pelas necessidades dos usuários, de acordo com seus contextos de vida. Projetos terapêuticos que respondam adequadamente ás demandas assistências e atuem como fatores de proteção, reduzindo a vulnerabilidade pessoal e social das pessoas com transtornos mentais e buscando estimular a participação social e a garantir o exercício dos direitos de cidadania dessa população (WHO, 1998, 2005).

Por sua complexidade, tais diretrizes ainda encontram limites para sua plena concretização. Nesse sentido a experiência nacional requer hoje investimentos específicos na modelagem dos serviços, definição de prioridades, limites e estilos de trabalho que possam contribuir na reprodutibilidade, sustentabilidade e continuidade das experiências. Necessita também de aprofundar a reflexão sobre a instabilidade das experiências bem sucedidas diante dos processos de mudança de gestão local.

São pontos que poderiam compor a agenda das iniciativas de formação, pois dependem para sua realização de atores instrumentalizados e capacitados para desempenharem papéis cada vez mais diferenciados nesse contexto.

\section{REFERENCIAS}

Brasil. Ministério da Educação. Conselho Nacional de Educação. Diretrizes Curriculares

Nacionais dos Cursos de Graduação [2001]. Disponível em: http://portal.mec.gov.br/cne/arquivos/pdf/CES04.pdf

Brasil, MS/ Portaria GM/MS n 1.996 , de 20 de agosto de 2007

WHO Checklist for evaluating a mental health plan, 2005. Disponível em http://www.who.int/mental_health/policy/essentialpackage1/ en/index $2 . h t m l$

Merhy, E. E. Engravidando palavras: o caso da integralidade. Palestra proferida no Congresso da Rede Unida, Belo Horizonte, 2005. Disponível em [http://www.uff.br/saudecoletiva/professores/ merhy/capitulos-06.pdf].

World Health Organization, Learning together to work together for health. Report of a WHO Study Group on Multiprofessional Education for Health Personnel. The Team Approach Technical Report Series 769. Geneva: WHO, 1988.

BRASIL. Ministério da Saúde. Secretaria de Atenção à Saúde/DAPE. Saúde Mental no SUS: acesso ao tratamento e mudança do modelo de atenção. Relatório de Gestão 2003-2006. Ministério da Saúde: Brasília, janeiro de 2007, 85p.

OMS/OPAS Relatório sobre a saúde no mundo- 2001. Saúde Mental: Nova concepção, Nova esperança,. Gráfica Brasil, Organização Mundial da Saúde, 2001. 